\title{
Diversity of cancer-related identities in long-term prostate cancer survivors after radical prostatectomy
}

\author{
Matthias Jahnen ${ }^{1}$, Eike Mynzak', Valentin H. Meissner ${ }^{1}$, Stefan Schiele ${ }^{1}$, Helga Schulwitz ${ }^{1}$, Donna P. Ankerst ${ }^{2}$, \\ Jürgen E. Gschwend ${ }^{1}$, Kathleen Herkommer ${ }^{1}$ and Andreas Dinkel ${ }^{3^{*}}$
}

\begin{abstract}
Background: Individuals affected by cancer need to integrate this experience into their personal biography as their life continues after primary therapy, leading to substantial changes in self-perception. This study identified factors uniquely associated with 5 different cancer-related identities in order to improve the understanding of how selfperception in men affected by prostate cancer is associated with certain clinical and psychosocial characteristics.

Methods: In this cross-sectional study, long-term prostate cancer survivors after radical prostatectomy were asked to choose one of 5 cancer-related identities that described them best. Associations with sociodemographic, clinical, and psychological variables were investigated using multivariable logistic regression.

Results: Three thousand three hundred forty-seven men (mean age 78.1 years) surveyed on average 15.6 years after prostatectomy were included. Most men favored the terms "someone who has had cancer" (43.9\%) which was associated with a mild disease course, and "patient" (26.3\%) which was associated with ongoing therapy and biochemical disease recurrence. The self-descriptions "cancer survivor" (16.8\%), "cancer conqueror" (10.9\%) and "victim" (2.1\%) were less common. "Cancer survivor" was associated with high perceived disease severity (OR: 1.86 [1.44-2.40]). "Cancer survivor" and "cancer conqueror" were related to high benefit finding (OR: 1.89 [1.48-2.40], OR: $1.46[1.12-1.89]$ respectively), and only "cancer conqueror" was associated with high well-being (OR: 1.84 [1.352.50]). Identification as "victim" was associated with a positive depression screening and low well-being (OR: 2.22 [1.15-4.31], OR: 0.38 [0.20-0.72] respectively) (all $p<0.05$ ).

Conclusions: Although long-term survival is common among men affected by PCa, they display a large diversity in cancer-related identities, which are associated with unique clinical and psychological characteristics. These cancerrelated identities and their distinctive properties are associated with psychological well-being even after a long follow-up.
\end{abstract}

Keywords: Prostate cancer, Cancer-related identity, Cancer survivors, Survivorship, Psychosocial adaptation

\footnotetext{
* Correspondence: a.dinkel@tum.de

${ }^{3}$ Department of Psychosomatic Medicine and Psychotherapy, Klinikum rechts der Isar, School of Medicine, Technical University of Munich, Langerstr.3, 81675 Munich, Germany

Full list of author information is available at the end of the article
}

(c) The Author(s). 2021 Open Access This article is licensed under a Creative Commons Attribution 4.0 International License, which permits use, sharing, adaptation, distribution and reproduction in any medium or format, as long as you give appropriate credit to the original author(s) and the source, provide a link to the Creative Commons licence, and indicate if changes were made. The images or other third party material in this article are included in the article's Creative Commons licence, unless indicated otherwise in a credit line to the material. If material is not included in the article's Creative Commons licence and your intended use is not permitted by statutory regulation or exceeds the permitted use, you will need to obtain permission directly from the copyright holder. To view a copy of this licence, visit http://creativecommons.org/licenses/by/4.0/. The Creative Commons Public Domain Dedication waiver (http://creativecommons.org/publicdomain/zero/1.0/) applies to the data made available in this article, unless otherwise stated in a credit line to the data. 


\section{Background}

With an aging population along with improvements in early detection and treatment, the numbers of individuals diagnosed with cancer, as well as successfully treated, continue to increase [1]. In many cases cancer diagnosis and treatment become part of a continuing life story rather than its final chapter. However, living with cancer is in many cases still accompanied by a wide range of hardships deriving from factors such as pain, therapy side effects, accelerated aging, existential fears and distrust in one's own body [2-5]. This has placed growing importance on advising individuals affected by cancer on how to process their cancer experience and how to integrate it into their personal biography $[6,7]$. In this regard, particularly in the U.S., the concept of survivorship and identification as a "cancer survivor" has been advocated, while other characterizations, such as "patient" or "cancer victim", which connotate with a passive stance, have become more and more outdated [68]. Accordingly, a shift away from these terms towards those that accentuate overcoming the disease, such as "cancer survivor" or "cancer conqueror", have been proposed for medical practice [7].

Deimling et al. found that self-identification as "survivor" was associated with increased positive affect, benefit finding and well-being in various types of cancers and that when given the choice, individuals affected by cancer often preferred the term "cancer survivor" over "patient". Consequently, they suggested that adapting a "survivor" identity is beneficial for mental health and disease coping [7]. However, subsequent research revealed that most individuals remain reluctant and identify more with the term "someone who has had cancer" than "cancer survivor" or "cancer conqueror" without a major drawback in overall well-being [8-10]. Therefore, it was suggested that actively trying to impose a cancer related identity (CRI) might cause more harm than benefit [11]. Additionally, it has been shown that individuals continuously affected by clinical or emotional symptoms after primary treatment for cancer tend to still perceive themselves as "patients" [12]. These mixed results complicate definitive recommendation of empowerment via specific CRIs.

Living with cancer is a major challenge for many men affected by prostate cancer (PCa). With 10-year survival almost unaltered in the majority of cases, long-term continuation of life after diagnosis has become the norm for men diagnosed with PCa $[13,14]$. Nevertheless, regular follow-up visits, biochemical tumor recurrence rate of 20 to $50 \% 10$ years after primary therapy, as well as side effects from primary and adjuvant therapy may be a burden for many of those men [15-17]. Thus, research on CRIs and their impact on well-being in men affected by PCa is of interest. Small US studies showed that 1 to 8 years after primary diagnosis, up to $35 \%$ of men affected by $\mathrm{PCa}$ favored the terms "cancer survivor" or "cancer conqueror "as self-description [8, 9]. While identification as a "survivor" was associated with positive affect, identification as a "victim" was associated with negative affect. Results suggested that lower threat appraisal, thoughtful reflection and gaining an understanding through peers might be contributing factors in adopting a "survivor" identity [7-9]. However, data on clinical factors as well as psychological characteristics that might accompany the development of certain CRIs, other than a "cancer survivor" one, are still lacking.

This study assessed how men affected by PCa selfidentify with regards to 5 different CRIs: "patient", "victim", "someone who has had cancer", "cancer survivor" and "cancer conqueror". These 5 CRIs carry different connotations with regards to one's personal cancer experience, which range from passive and submissive to actively engaging. Assessment of such a balanced set of CRIs allowed a detailed comparison between men, who adapt an active CRI, with men, who identify with a submissive or a neutral CRI. Furthermore, associations of these CRIs with a broad set of sociodemographic characteristics, clinical factors, and psychosocial aspects were investigated, using data from a large German PCa database.

\section{Methods \\ Design and procedure}

Data were gathered as part of the German research project 'Familial Prostate Cancer', which since 1993 has prospectively recruited $\mathrm{PCa}$ patients regardless of a family history of PCa via collaborating urologists and clinics. Further details about the research project and its multicentric database has been described elsewhere $[15,18]$. In short, participants receive annual questionnaires (conducted in German) concerning clinical, sociodemographic, and psychosocial information, with further clinical information being obtained through the corresponding treating urologist. The ethic committee of the TU Munich has approved this research project.

For the present study, cross-sectional data from the annual follow-up of 2019 were analyzed. By January of 2020, 4141 of 6168 participants $(67.1 .0 \%)$ had returned the questionnaire. From these, only participants who underwent radical prostatectomy as primary treatment and who answered the item regarding cancer identity with a single answer were included $(N=3347)$.

\section{Measures}

\section{Cancer-related identity}

Following previous research on men affected by $\mathrm{PCa}$, participants were asked to choose only one of the following 5 CRIs describing them most suitable with 
regards to their cancer experience [7, 8, 11]: "patient", "victim", "someone who has had cancer", "cancer survivor" and "cancer conqueror".

\section{Sociodemographic and clinical characteristics}

Sociodemographic data included: age at survey, school education, current partnership, and children. Clinical data included age at surgery, time since surgery, presence of a second primary cancer, family history of $\mathrm{PCa}$ (yes: at least one consanguine relative with $\mathrm{PCa}$ vs. no), PSA level at diagnosis, histopathological Gleason-Score, histopathological grading, organ-confined stage at RP according to TNM classification of 2002, biochemical recurrence (PSA level $\geq 0.2 \mathrm{ng} / \mathrm{ml}$ ) during follow-up, biochemical recurrence at survey, discontinued PSA follow-up and ongoing PCa treatment at survey.

\section{Depression and anxiety}

Symptoms of depression and anxiety were assessed using the validated ultra-brief instruments Patient Health Questionnaire-2 (PHQ-2) and General Anxiety Disorder-2 (GAD-2) scale. For both scales (range 0-6), a cut-off score $\geq 3$ indicates a clinical level of depression or anxiety, respectively $[19,20]$. Cronbach's alpha coefficients for PHQ-2 and GAD-2 scale were 0.65 and 0.75 respectively, representing satisfactory internal consistency.

\section{Perceived severity of the disease}

The perceived severity of being affected by PCa was assessed with the single item "Having had prostate cancer is one of the worst things that happened to me in my life" (adapted from [21] using past tense). Participants were asked to answer on a four-point scale ranging from 'strongly disagree' (1) to 'strongly agree' (4). Responses (1) and (2) and responses (3) and (4) were combined to 'low perceived severity' and 'high perceived severity', respectively.

\section{Benefit finding}

Benefit finding was assessed using one item with high factor loading and high face validity adapted from the German version of the 17 -item benefit finding scale: "My prostate cancer has helped me become more focused on priorities, with a deeper sense of purpose in life" [22, 23]. Participants were asked to answer on a five-point scale ranging from 'not at all' (1) to 'extremely' (5). Responses (1) and (2) and (3) to (5) were combined to 'low benefit finding' and 'high benefit finding', respectively [24].

\section{Well-being}

Well-being was assessed using the single item" How much of the time during the past month did you feel happy" [25]. Participants were asked to answer on a four-point scale ranging from 'none' (1) to 'all' (4). Responses (1) and (2) and (3) and (4) were combined to 'low well-being' and 'high well-being', respectively.

\section{Statistical analysis}

Descriptive statistics were calculated for all study variables. Chi-square and Wilcoxon tests were applied for analyzing associations between the CRIs and sociodemographic, clinical, and psychological variables. Multivariable logistic regression with backward elimination was used to identify variables independently associated with each of the CRIs. All psychosocial and sociodemographic variables as well as certain clinical characteristics (time since surgery, family history of $\mathrm{PCa}$, second primary tumor, biochemical tumor recurrence during follow-up and survey, ongoing therapy) were included in multivariable logistic regression analysis. Statistical significance was set at $p<0.05$. All analyses were performed using SAS (Version 9.4).

\section{Results}

Three thousand three hundred forty-seven men affected by $\mathrm{PCa}$ with a mean age at survey of 78.1 years (standard deviation $(\mathrm{SD})=6.3$ ) and a mean follow-up of 15.6 years $(\mathrm{SD}=3.8)$ were included in the analysis (Table 1$)$. Men self-identified most frequently as "someone who has had cancer" (43.9\%) followed by "patient" (26.3\%). The terms "cancer survivor" and "cancer conqueror" were favored by 16.8 and $10.9 \%$, respectively. "Victim" was the least endorsed term (2.1\%) (Fig. 1).

Men who self-identified as "someone who has had cancer" were the youngest at survey, while men who self-identified as "cancer survivor" were the oldest. Other sociodemographic variables such as partnership or children did not show any significant differences between the different CRIs. Men who self-identified as "someone who has had cancer" had the lowest percentage of biochemical recurrence during follow-up (31.6\% vs. $40.9 \%$ on average). High perceived severity of the disease was reported most frequently by men self-identified as "cancer survivor" (68.9\%) and "victim" (82.2\%). While men self-identified as "cancer conqueror" expressed most often high well-being (75.2\%), men self-identified as "cancer survivor" and "victim" expressed high well-being least often (59.0 and 34.8\%, respectively). High benefit finding was found most often in men self-identified as "cancer survivor" or "cancer conqueror" (56.1, 51.4\%, respectively vs $44.0 \%$ on average). (all $p<0.0001$ ) (Table 2).

Multivariable logistic regression analyses showed almost no associations between sociodemographic factors and the 5 CRIs. The two exceptions were an association between a "survivor" identity and higher age at survey and an association between identification as "someone 
Table 1 Sociodemographic, clinical and psychological characteristics of the study sample $(n=3347)$

n $\%$

Sociodemographic factors

Age at survey (years) $\mathrm{M}=78.1, \mathrm{SD}=6.3$

$\leq 70$

$>70 \leq 80$

1599

$>80$

1373

Educational level

primary, secondary - low

1187

secondary - intermediate

519

secondary - high

362

tertiary

911

Partnership

yes

no

3053

260

Children

0

$\geq 1$

376

2901

Clinical characteristics

Age at surgery (years) $\mathrm{M}=62.5, \mathrm{SD}=6.1$

$\leq 55$

$>55 \leq 65$

1742

$>65$

1206

Time since surgery (years) $M=15.6, S D=3.8$

$\leq 10$

$>10 \leq 15$

1425

$>15 \leq 20$

1349

$>20$

375

Second primary cancer

yes

430

no

2917

Family history of $\mathrm{PCa}$

yes

1297

no

2050

PSA level at diagnosis $(\mathrm{ng} / \mathrm{ml})$

$$
\leq 4
$$

$>4 \leq 10$

1870

$>10$

934

Gleason score

$$
\text { 2-6 }
$$

$7,3+4=7,4+3=7$

1424

1131

$8-10$

269

Grading

GI

G II
Table 1 Sociodemographic, clinical and psychological characteristics of the study sample $(n=3347)$ (Continued)

\begin{tabular}{lll}
\hline & $\mathbf{n}$ & $\%$ \\
\hline G III & 833 & 25.6 \\
$\begin{array}{l}\text { Organ-confined stage at RP } \\
\text { yes }\end{array}$ & 2343 & 71.0 \\
no & 955 & 29.0 \\
Biochemical recurrence during follow-up & & \\
$\quad$ yes & 1211 & 40.9 \\
no & 1749 & 59.1 \\
Biochemical recurrence at survey & & 20.0 \\
$\quad$ yes & 572 & 80.0 \\
no & 2295 & \\
Discontinued PSA follow-up & & 5.6 \\
yes & 186 & 94.4 \\
no & 3161 & \\
Ongoing treatment at survey & & 12.9 \\
yes & 423 & \\
no & 2864 &
\end{tabular}

Psychosocial factors

PHQ-2 (depression screening)

positive screening $(\geq 3)$

469

14.8

negative screening $(<3)$

2707

85.2

GAD-2 (anxiety disorder screening)

positive screening $(\geq 3)$

360

11.4

negative screening $(<3)$

2798

88.6

Perceived severity of disease

low

1448

45.0

high

1770

55.0

Well-being

12.9

low

1075

34.2

high

2067

65.8

Benefit Finding

38.8

61.2

low

1823

56.0

high

1429

44.0

Note: $M$ mean, $S D$ standard deviation, $P C a$ prostate cancer, $P S A$ prostate specific antigen, $R P$ radical prostatectomy, $P H Q$ patient health questionnaire, $G A D$ general anxiety disorder

60.1

30.0

who had cancer" and higher school education. Although associations between clinical factors and the CRIs were seldom, there were the following notable exceptions. While men identifying as "someone who has had cancer" were less likely to have faced a more complicated followup (biochemical recurrence or ongoing therapy), men identifying as "patient" were more likely to experience a current disease progress or ongoing therapy. Men with a "cancer survivor" identity were more likely to have experienced a biochemical recurrence during follow-up, but 


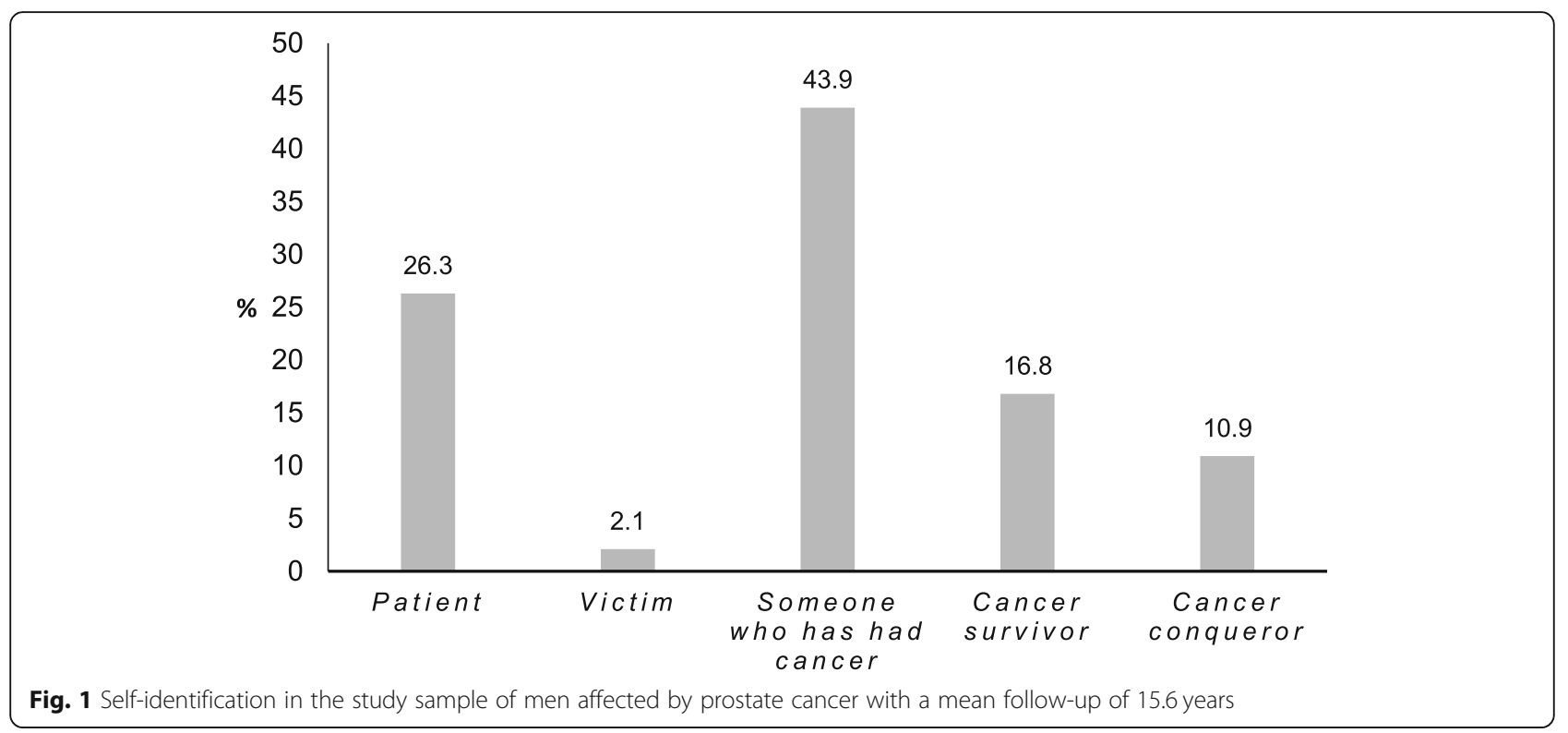

were less likely to have a current biochemical recurrence at survey (Table 3) (all $p<.05)$.

Associations with psychosocial factors were present for all CRIs. Whereas men with a "cancer survivor" or "cancer conqueror" identity were more likely to be considered to have high benefit finding, men identifying as "someone who has had cancer" or "patient" were less likely to be considered to have high benefit finding. Selfidentification as "cancer survivor" was also associated with an increased likelihood of high perceived disease severity and a decreased likelihood of high well-being. "Cancer conqueror" was the only CRI associated with an increased likelihood of high well-being. Men selfidentified as "victim" were more likely to report high perceived disease severity and have a positive screening for depression. The identities "conqueror" and "victim" were associated with the least number of significant factors (Table 3$)$ (all $p<.05)$.

\section{Discussion}

During the past decades growing focus has been placed on assisting individuals diagnosed with cancer on coping with the disease as they continue their life beyond the stage of primary therapy and successful recovery. In this regard it has been shown that there are different ways of perceiving this experience, leading to a variety of cancer-related identities (CRIs). Especially meaning making by adopting an active CRI and identifying as a "cancer survivor" has been advocated as beneficial [7-9].

In this analysis of men affected by prostate cancer (PCa) with a long follow-up after radical prostatectomy, most men self-identified with the more neutral terms "someone who has had cancer" or "patient", while only one forth self-identified as "cancer survivor" or "cancer conqueror". Only few men believed that "victim" would describe them best. These results are in accordance with previous research on men affected by PCa showing that, while the majority of such men favors a more neutral term such as "someone who has had cancer" as selfdescription, identification with regards to a cancer experience may vary widely $[8,9]$. Nevertheless, it has to be pointed out that the endorsement of a "cancer survivor" identity was relatively low in our sample compared to previous research, which has mostly been done in the US $[8,11]$. Outside of the US the term "cancer survivor" has been advocated less publicly as a positive empowering term. It has been shown that without this cultural background individuals affected by cancer might associate the term "survivor" or its literal translation with survival of natural disasters or military conflict and deem it as inappropriate to their situation [26-28]. This might have led to the low endorsement of the term in our sample of German men affected by PCa. However, as we applied a forced choice response, we do not know whether men would find other self-descriptions nearly equally appropriate. Thus, CRI not chosen do not necessarily imply negative appraisals.

Results indicated that men who preferred the more neutral term "someone who has had cancer" were more likely to have experienced PCa with an oncological uneventful follow-up (no biochemical recurrence) and less likely to report profound, positive changes derived from their cancer experience (benefit finding). These findings support previous studies finding that individuals who preferred a more neutral term considered their disease often as something unthreatening of their past and "hardly ever think about their disease" [10]. For men 
Table 2 Comparison of key characteristics of the 5 cancer-related identities

\begin{tabular}{|c|c|c|c|c|c|}
\hline & $\begin{array}{l}\text { Someone who has had } \\
\text { cancer } n=1468(\%)\end{array}$ & $\begin{array}{l}\text { Patient } \\
n=882 \\
(\%)\end{array}$ & $\begin{array}{l}\text { Cancer survivor } n=561 \\
\text { (\%) }\end{array}$ & $\begin{array}{l}\text { Cancer conqueror } n=364 \\
\text { (\%) }\end{array}$ & $\begin{array}{l}\text { Victim } \\
n=72 \\
(\%)\end{array}$ \\
\hline \multicolumn{6}{|l|}{ Age at survey (years)** } \\
\hline$\leq 70$ & 12.7 & 10.2 & 7.8 & 13.2 & 9.7 \\
\hline$>70 \leq 80$ & 49.4 & 48.2 & 43.5 & 45.9 & 52.8 \\
\hline$>80$ & 37.9 & 41.6 & 48.7 & 40.9 & 37.5 \\
\hline \multicolumn{6}{|l|}{ Educational level** } \\
\hline primary, secondary - low & 36.3 & 38.8 & 46.0 & 45.1 & 52.5 \\
\hline secondary - intermediate & 17.9 & 17.3 & 15.4 & 19.0 & 16.4 \\
\hline secondary - high & 12.5 & 11.9 & 12.8 & 10.2 & 13.1 \\
\hline tertiary & 33.3 & 32.0 & 25.8 & 25.7 & 18.0 \\
\hline \multicolumn{6}{|l|}{ Partnership } \\
\hline yes & 92.2 & 91.9 & 90.7 & 95.0 & 91.4 \\
\hline no & 7.8 & 8.1 & 9.3 & 5.0 & 8.6 \\
\hline \multicolumn{6}{|l|}{ Children } \\
\hline 0 & 12.1 & 12.8 & 9.3 & 9.9 & 8.5 \\
\hline$\geq 1$ & 87.9 & 87.2 & 90.7 & 90.1 & 91.5 \\
\hline \multicolumn{6}{|l|}{ Age at surgery (years) } \\
\hline$\leq 55$ & 13.8 & 10.0 & 8.9 & 13.5 & 12.5 \\
\hline$>55 \leq 65$ & 52.1 & 51.7 & 51.7 & 52.7 & 55.6 \\
\hline$>65$ & 34.1 & 38.3 & 39.4 & 33.8 & 31.9 \\
\hline \multicolumn{6}{|l|}{ Time since surgery (years)*** } \\
\hline$\leq 10$ & 5.7 & 6.8 & 5.5 & 5.8 & 4.2 \\
\hline$>10 \leq 15$ & 44.3 & 42.2 & 36.0 & 46.4 & 43.0 \\
\hline$>15 \leq 20$ & 40.7 & 40.8 & 41.7 & 34.9 & 41.7 \\
\hline$>20$ & 9.3 & 10.2 & 16.8 & 12.9 & 11.1 \\
\hline \multicolumn{6}{|l|}{ Second primary cancer } \\
\hline yes & 11.7 & 12.5 & 15.5 & 13.7 & 16.7 \\
\hline no & 88.3 & 87.5 & 84.5 & 86.3 & 83.3 \\
\hline \multicolumn{6}{|l|}{ Family history of $P C a$} \\
\hline yes & 40.5 & 35.9 & 38.2 & 40.4 & 33.3 \\
\hline no & 59.5 & 64.1 & 61.8 & 59.6 & 66.7 \\
\hline \multicolumn{6}{|c|}{ Biochemical recurrence during $F U^{* * * *}$} \\
\hline yes & 31.6 & 49.1 & 51.3 & 39.6 & 54.1 \\
\hline no & 68.4 & 50.9 & 48.7 & 60.4 & 45.9 \\
\hline \multicolumn{6}{|c|}{ Biochemical recurrence at survey****} \\
\hline yes & 13.7 & 29.6 & 21.9 & 16.8 & 25.9 \\
\hline no & 86.3 & 70.4 & 78.1 & 83.2 & 74.1 \\
\hline \multicolumn{6}{|l|}{ Discontinued PSA follow-up } \\
\hline yes & 5.3 & 5.1 & 6.6 & 5.5 & 9.7 \\
\hline no & 94.7 & 94.9 & 93.4 & 94.5 & 90.3 \\
\hline \multicolumn{6}{|c|}{ Ongoing treatment at survey****} \\
\hline yes & 6.2 & 19.7 & 18.3 & 13.0 & 23.2 \\
\hline no & 93.8 & 80.3 & 81.7 & 87.0 & 76.8 \\
\hline
\end{tabular}


Table 2 Comparison of key characteristics of the 5 cancer-related identities (Continued)

\begin{tabular}{|c|c|c|c|c|c|}
\hline & $\begin{array}{l}\text { Someone who has had } \\
\text { cancer } n=1468(\%)\end{array}$ & $\begin{array}{l}\text { Patient } \\
n=882 \\
\text { (\%) }\end{array}$ & $\begin{array}{l}\text { Cancer survivor } n=561 \\
\text { (\%) }\end{array}$ & $\begin{array}{l}\text { Cancer conqueror } n=364 \\
\text { (\%) }\end{array}$ & $\begin{array}{l}\text { Victim } \\
n=72 \\
(\%)\end{array}$ \\
\hline \multicolumn{6}{|c|}{ PHQ-2 (depression screening) **** } \\
\hline positive screening $(\geq 3)$ & 12.0 & 15.0 & 19.7 & 13.0 & 39.1 \\
\hline negative screening $(<3)$ & 88.0 & 85.0 & 80.3 & 87.0 & 60.9 \\
\hline \multicolumn{6}{|c|}{ GAD-2 (anxiety disorder screening) **** } \\
\hline positive screening $(\geq 3)$ & 9.7 & 10.2 & 16.2 & 8.7 & 37.3 \\
\hline negative screening $(<3)$ & 90.3 & 89.8 & 83.8 & 91.3 & 62.7 \\
\hline \multicolumn{6}{|c|}{ Perceived severity of disease ${ }^{* * * *}$} \\
\hline low & 48.4 & 50.6 & 31.1 & 44.5 & 18.8 \\
\hline high & 51.6 & 49.4 & 68.9 & 55.5 & 82.2 \\
\hline \multicolumn{6}{|l|}{ Well-being ${ }^{* * * *}$} \\
\hline low & 32.3 & 34.5 & 41.0 & 24.8 & 65.2 \\
\hline high & 67.7 & 65.5 & 59.0 & 75.2 & 34.8 \\
\hline \multicolumn{6}{|l|}{ Benefit finding ${ }^{* * * *}$} \\
\hline low & 59.6 & 60.6 & 43.9 & 48.6 & 58.6 \\
\hline high & 30.4 & 39.4 & 56.1 & 51.4 & 41.4 \\
\hline
\end{tabular}

Note: ${ }^{* * *} p<.0001 ;{ }^{* *} p<.001 ;{ }^{* *} p<.01 ;{ }^{*} p<.05 ; P C a$ prostate cancer, FU follow-up, PSA prostate specific antigen, PHQ patient health questionnaire, GAD general anxiety disorder, per. perceived

who self-identified as "someone who has had cancer", PCa did not hold the centrality in their life sufficient to trigger the development of an active CRI [29]. Since PCa is generally linked with long-term survival, many men prefer "someone who has had cancer" over terms such as "cancer survivor" as self-description in the present as well as in previous studies [11].

A characteristic adversity of PCa is that, despite an excellent survival prognosis, biochemical cancer recurrence, requiring subsequent therapy, is seen in a considerable number of cases even 10 years after primary therapy $[17,30]$. In this study sample at least a fifth reported a biochemical cancer recurrence at survey and/or an ongoing therapy. Men in this situation, characterized by cancer as a current medical condition rather than a previous life event, were more likely to perceive themselves as "patient". This agrees with a study from Thong et al., showing that treatment, cancer recurrence or lingering cancer/therapy-related symptoms after primary cancer therapy were associated with self-identification as "patient" [12]. Men who self-identified as "patient" were less likely to consider their disease to have high severity, and no association between self-identification as "patient" and psychological distress was found. In contrast to previous studies, this suggests that identification with the more passive term "patient" is not necessarily associated with a more demanding disease burden and that a general disapproval of the term for individuals affected by cancer might be premature $[10,12]$.
In scientific literature individuals affected by cancer following primary therapy are regularly referred to as "cancer survivors" [27, 28]. The term is often used for certain time frames (most often 3 or 5 years) without signs of cancer recurrence, which indicate that individuals affected by cancer might be considered as cured. With growing research on cancer survivorship, the term "cancer survivor" has also been advocated as proper description of individuals affected by cancer regardless of their disease course in order to emphasize resilience and personal strength in one's "fight" against cancer [28, 31]. Especially in the U.S., such an interpretation of the term "cancer survivor" has been promoted and individuals affected by cancer have been encouraged to adopt the term as self-description [11]. Some studies on cancer survivorship and CRIs have already indicated that adapting the identity of a "survivor" is a sign of actively engaging and coping with the cancer experience, which might lead to psychological benefits for the affected individual [7].

Analyses of narrative data have suggested, on the one hand, that identification as "cancer survivor" is often based on having experienced the disease as a serious life event and, on the other hand, a feeling of having successfully overcome the disease [7,32]. These aspects are supported by the findings of this study showing that men who self-identified as "cancer survivor" were inclined to report high perceived disease severity. Further, these men were also more likely to have endured a 
Table 3 Factors associated with cancer-related identities in multiple logistic regression analysis

\begin{tabular}{|c|c|c|c|c|c|}
\hline & $\begin{array}{l}\text { Someone who has had cancer } \\
\text { OR }[95 \% \mathrm{CI}]\end{array}$ & $\begin{array}{l}\text { Patient } \\
\text { OR }[95 \% \mathrm{Cl}]\end{array}$ & $\begin{array}{l}\text { Cancer survivor } \\
\text { OR }[95 \% \mathrm{Cl}]\end{array}$ & $\begin{array}{l}\text { Cancer conqueror } \\
\text { OR }[95 \% \mathrm{Cl}]\end{array}$ & $\begin{array}{l}\text { Victim } \\
\text { OR [95\% Cl] }\end{array}$ \\
\hline \multicolumn{6}{|c|}{ Age at survey (years) [ref: $\leq 70]$} \\
\hline$>70 \leq 80$ & - & - & $1.47[0.98-2.22]$ & - & - \\
\hline$>80$ & - & - & $2.11[1.39-3.20]$ & - & - \\
\hline \multicolumn{2}{|c|}{ Educational level [ref: primary, sec. low] } & - & & & \\
\hline Secondary intermediate & $1.37[1.07-1.76]$ & - & - & - & - \\
\hline Secondary high & $1.16[0.87-1.54]$ & - & - & - & - \\
\hline Tertiary & $1.34[1.09-1.65]$ & - & - & - & - \\
\hline \multicolumn{6}{|l|}{ Family history of PCa [ref: no] } \\
\hline yes & $1.20[1.00-1.43]$ & - & - & - & - \\
\hline \multicolumn{6}{|c|}{ Biochemical recurrence during FU [ref: no] } \\
\hline yes & $0.56[0.46-0.68]$ & - & $1.97[1.49-2.61]$ & - & - \\
\hline \multicolumn{6}{|c|}{ Biochemical recurrence at survey [ref: no] } \\
\hline yes & - & $1.93[1.53-2.44]$ & $0.68[0.48-0.95]$ & - & - \\
\hline \multicolumn{6}{|c|}{ Ongoing treatment at survey [ref: no] } \\
\hline yes & $0.37[0.27-0.51]$ & $1.90[1.45-2.47]$ & - & - & $2.07[1.06-4.04]$ \\
\hline \multicolumn{6}{|c|}{ PHQ-2 (depression screening) [ref: negative screening $(<3)]$} \\
\hline positive screening $(\geq 3)$ & - & - & - & - & $2.22[1.15-4.31]$ \\
\hline \multicolumn{6}{|c|}{ Perceived severity of disease [ref: low] } \\
\hline high & - & $0.75[0.61-0.91]$ & $1.86[1.44-2.40]$ & - & - \\
\hline \multicolumn{6}{|l|}{ Well-being [ref: low] } \\
\hline high & - & - & $0.77[0.61-0.99]$ & $1.84[1.35-2.50]$ & $0.38[0.20-0.72]$ \\
\hline \multicolumn{6}{|l|}{ Benefit finding [ref: low] } \\
\hline high & $0.79[0.66-0.94]$ & $0.75[0.62-0.92]$ & $1.89[1.48-2.40]$ & $1.46[1.12-1.89]$ & - \\
\hline
\end{tabular}

Note: $P C a$ prostate cancer, $P H Q$ Patient Health Questionnaire, FU follow-up, ref reference, OR odds ratio, $C /$ confidence interval, sec. secondary

biochemical recurrence during follow-up, while simultaneously being more likely to be biochemical recurrence-free at survey. This supports that overcoming a subjectively and objectively more stressing disease course may lead to the endorsement of a "survivor" identity. Moreover, previous research has suggested that adapting a "survivor" identity may bring forward positive changes driven by the disease experience $[7,10]$. These assumptions are supported by findings of this study showing an association between a "survivor" identification and high benefit finding. However, men favoring the self-description as "survivor" were also less likely to report high well-being. These results contradict previous findings proposing a positive effect of adopting a "survivor" identity on psychological health and well-being. Consequently, findings here show that the implications of a "survivor" orientation may vary between individuals affected by cancer.

A previous review of CRIs pointed out that acceptance of the term "cancer survivor" derives partly from positive portrayal of the concept by survivorship movements in the media and support groups [11]. It should be noted that cancer survivor culture and research on CRIs is mostly based in the U.S., while cultivation of the term "survivor" or its equivalent translations is rather seldom in Europe [11, 33]. Limited exposure to a positive depiction of survivorship might lead to interindividual and intercultural differences in the understanding of the term and concept [34]. One should consider that without reference some individuals may choose a "cancer survivor" identity not as a sign of active coping, but rather to reflect the burden of being confronted by fundamental changes and a sense of near defeat derived from their cancer experience. Therefore, identification as "cancer survivor" might be for some an expression or even a cause of reduced psychological well-being.

Since the term "cancer survivor" and its literal translation might be subject to interpretation depending on the cultural background, the term "cancer conqueror", which puts further emphasis on actively engaging and defeating the disease, was also included as potential CRI in this analysis. Previous studies that have investigated the term "cancer conqueror" have shown that endorsement of such an energetic CRI might be associated with 
positive affect and psychological well-being $[8,11]$. In contrast to identification as a "cancer survivor", which seems to be influenced by an objectively and subjectively demanding disease course, endorsement of the term "cancer conqueror" was not associated with any clinical factors or the perceived disease severity. This suggests that adapting this kind of identity might not be based on a certain disease course but rather on individual traits influencing the general outlook on life. This is supported by findings here showing that identification as a "cancer conqueror" is associated with high well-being as well as high benefit finding, which may reflect a generally optimistic attitude.

As in previous studies of men affected by PCa only a minority self-identified with the term "victim", stressing the seemingly pitiful fate of individuals diagnosed with cancer $[8,9]$. Most studies on the subject have found that endorsement of this submissive CRI is associated with psychological distress [7-10]. This is supported by the findings from this analysis showing that men selfidentifying as "victim" were more likely to perceive the severity of their disease as high, and were more likely to have positive depression screening and low well-being. Our statistical findings have to be treated with caution due to the low number of men identifying as "victim", nevertheless these men seem to be burdened most by their cancer experience and seem in need of further psychological support, even years after primary diagnosis and therapy.

Study findings must be considered within the limitations of the analysis. Limited by the cross-sectional design, causal assumptions on development of CRIs should be further investigated in longitudinal studies. Further, self-perception with regard to one's cancer experience might also be a dynamic process and changes over time should be expected. Such developments cannot be observed by the applied study design and require further investigation. Nevertheless, it should be noted that multi-variable logistic regression analysis for all 5 CRIs was controlled for the time since surgery, but did not yield any significant results with regards to this parameter. This suggests that in our sample of men with a rather long follow-up after primary therapy, CRIs may be considered as somewhat stable. By only including men primarily treated with radical prostatectomy generalization towards all men affected by $\mathrm{PCa}$ is limited and implications for other cancer types should be treated with caution. Further, it has to be noted that limited by the available space of the annual questionnaires some psychological variables were measured using single items. Although this might decrease the validity of our measured psychological variables, previous research has shown that using single items can produce highly credible measurements when longer questionnaire cannot be applied [35, 36]. The variety in CRIs suggests that different terms may be equally appropriate in addressing men affected by PCa and that, though these men select a preferred identity when prompted, the remaining identities do not necessarily have negative connotations, and when given the choice some men would have picked several identities to describe themselves with regard to their cancer experience. Nevertheless, the CRIs were distinctively associated with different clinical circumstances and psychological factors, implying a clinically relevant differences in CRIs of men affected by PCa.

\section{Conclusion}

Although long-term survival is common among men affected by $\mathrm{PCa}$, they display a large diversity in CRIs that show unique associations with mainly clinical and psychological characteristics. These CRIs and their distinctive properties are present and seem to interact with psychological well-being even after a long follow-up. This demonstrates that an individual approach, which should include the evaluation of the patient's cancer related identity, is essential in the post-clinical care of men affected by $\mathrm{PCa}$ in order to understand the personal impact of their cancer experience.

\section{Abbreviations}

CRI: Cancer-related identity; PCa: Prostate cancer

\section{Acknowledgments}

No further acknowledgments.

\section{Authors' contributions}

The authors listed below have made substantial contributions to the intellectual content of the paper in the various sections described below. Conception and design: A. Dinkel, K. Herkommer, M. Jahnen, V. H. Meissner. Acquisition of data: E. Mynzak, K. Herkommer. Analysis and interpretation of data: M. Jahnen, K. Herkommer, A. Dinkel, E. Mynzak. Drafting of the manuscript: M. Jahnen, E. Mynzak. Critical revision of the manuscript for important intellectual content: A. Dinkel, V. H. Meissner, K. Herkommer, E. Mynzak, S. Schiele, H. Schulwitz, D.P. Ankerst, J.E. Gschwend. Statistical analysis: S. Schiele, H. Schulwitz. Administrative, technical, or material support: K. Herkommer, J. E. Gschwend. Supervision: A. Dinkel, K. Herkommer. The authors read and approved the final manuscript.

\section{Funding}

No external funding received. Open Access funding enabled and organized by Projekt DEAL.

\section{Availability of data and materials}

This manuscript contains all associated data.

\section{Declarations}

Ethics approval and consent to participate

The ethic committee of the TU Munich has approved this study and the underlying research project. All participants gave their written consent to the research project. All methods were carried out in accordance with the Helsinki declaration.

Consent for publication

Not applicable. 


\section{Competing interests}

All authors (Matthias Jahnen, Eike Mynzak, Valentin H. Meissner, Stefan Schiele, Helga Schulwitz, Donna P. Ankerst, Jürgen E. Gschwend, Kathleen Herkommer, and Andreas Dinkel) have nothing to disclose.

\section{Author details}

'Department of Urology, Klinikum rechts der Isar, School of Medicine, Technical University of Munich, Ismaninger Str. 22, 81675 Munich, Germany. ${ }^{2}$ Department of Mathematics, Technical University of Munich, Boltzmannstr. 3, 85748 Garching, Germany. ${ }^{3}$ Department of Psychosomatic Medicine and Psychotherapy, Klinikum rechts der Isar, School of Medicine, Technical University of Munich, Langerstr.3, 81675 Munich, Germany.

Received: 25 April 2021 Accepted: 8 September 2021 Published online: 20 September 2021

\section{References}

1. Miller KD, Nogueira L, Mariotto AB, Rowland JH, Yabroff KR, Alfano CM, et al. Cancer treatment and survivorship statistics, 2019. CA Cancer J Clin. 2019; 69(5):363-85. https://doi.org/10.3322/caac.21565.

2. Shapiro CL. Cancer survivorship. N Engl J Med. 2018;379(25):2438-50. https://doi.org/10.1056/NEJMra1712502.

3. Jung A, Nielsen ME, Crandell JL, Palmer MH, Smith SK, Bryant AL, et al. Health-related quality of life among non-muscle-invasive bladder cancer survivors: a population-based study. BJU Int. 2020;125(1):38-48. https://doi. org/10.1111/bju.14888

4. Bernat JK, Wittman DA, Hawley ST, Hamstra DA, Helfand AM, Haggstrom DA, et al. Symptom burden and information needs in prostate cancer survivors: a case for tailored long-term survivorship care. BJU Int. 2016; 118(3):372-8. https://doi.org/10.1111/bju.13329.

5. Dinkel A, Herschbach P. Fear of progression in cancer patients and survivors. Recent Results Cancer Res. 2018;210:13-33. https://doi.org/10.1 007/978-3-319-64310-6_2.

6. Little M, Paul K, Jordens CFC, Sayers EJ. Survivorship and discourses of identity. Psychooncology. 2002;11(2):170-8. https://doi.org/10.1002/pon.549.

7. Deimling GT, Bowman KF, Wagner LJ. Cancer survivorship and identity among long-term survivors. Cancer Invest. 2007;25(8):758-65. https://doi. org/10.1080/07357900600896323.

8. Bellizzi KM, Blank TO. Cancer-related identity and positive affect in survivors of prostate cancer. J Cancer Surviv. 2007;1(1):44-8. https://doi.org/10.1007/ s11764-007-0005-2

9. Morris BA, Lepore SJ, Wilson B, Lieberman MA, Dunn J, Chambers SK. Adopting a survivor identity after cancer in a peer support context. J Cancer Surviv. 2014;8(3):427-36. https://doi.org/10.1007/s11764-014-0355-5.

10. Park CL, Zlateva I, Blank TO. Self-identity after cancer: "survivor", "victim", "patient", and "person with cancer". J Gen Intern Med. 2009;24(Suppl 2): S430-5. https://doi.org/10.1007/s11606-009-0993-x.

11. Cheung SY, Delfabbro P. Are you a cancer survivor? A review on cancer identity. J Cancer Surviv. 2016;10(4):759-71. https://doi.org/10.1007/s11764-016-0521-z.

12. Thong MSY, Wolschon EM, Koch-Gallenkamp L, Waldmann A, WaldeyerSauerland M, Pritzkuleit R, et al. "Still a Cancer Patient"-Associations of Cancer Identity With Patient-Reported Outcomes and Health Care Use Among Cancer Survivors. JNCI Cancer Spectr. 2018;2(2):pky031.

13. N. Mottet RCNvdB, E. Briers, P. Cornford, M. De Santis, S. Fanti, S. Gillessen, J. Grummet, A.M. Henry, T.B. Lam, M.D. Mason, T.H. van der Kwast, H.G. van der Poel, O. Rouvière, D. Tilki, T. Wiegel, T. Van den Broeck, M. Cumberbatch, N. Fossati, T. Gross, M. Lardas, M. Liew, L. Moris, I.G. Schoots, P-P.M. Willemse EAU - EANM - ESTRO - ESUR - SIOG Guidelines on Prostate Cancer. 2019.

14. Howlader N, Noone AM, Krapcho M, Miller D, Brest A, Yu M, Ruhl J, Tatalovich Z, Mariotto A, Lewis DR, Chen HS, Feuer EJ, Cronin KA. SEER Cancer Statistics Review, 1975-2016, National Cancer Institute. Bethesda: https://seer.cancer.gov/csr/1975_2016/, based on November 2018 SEER data submission, posted to the SEER web site, April 2019.

15. Meissner VH, Herkommer K, Marten-Mittag B, Gschwend JE, Dinkel A. Prostate cancer-related anxiety in long-term survivors after radical prostatectomy. J Cancer Surviv. 2017;11(6):800-7. https://doi.org/10.1007/s11764-017-0619-y.

16. Johansson E, Steineck G, Holmberg L, Johansson JE, Nyberg T, Ruutu M, et al. Long-term quality-of-life outcomes after radical prostatectomy or watchful waiting: the Scandinavian Prostate Cancer Group-4 randomised trial. Lancet Oncol. 2011;12(9):891-9. https://doi.org/10.1016/S1470-2045(11 )70162-0.
17. Liesenfeld L, Kron M, Gschwend JE, Herkommer K. Prognostic factors for biochemical recurrence more than 10 years after radical prostatectomy. J Urol. 2017;197(1):143-8. https://doi.org/10.1016/j.juro.2016.07.004.

18. Paiss T, Herkommer K, Bock B, Heinz H, Vogel W, Kron M, et al. Association between the clinical presentation and epidemiological features of familial prostate cancer in patients selected for radical prostatectomy. Eur Urol. 2003;43(6):615-21. https://doi.org/10.1016/S0302-2838(03)00146-5.

19. Kroenke K, Spitzer RL, Williams JBW. The Patient Health Questionnaire-2 validity of a two-item depression screener. Med Care. 2003;41(11):1284-92. https://doi.org/10.1097/01.MLR.0000093487.78664.3C.

20. Kroenke K, Spitzer RL, Williams JBW, Monahan PO, Lowe B. Anxiety disorders in primary care: prevalence, impairment, comorbidity, and detection. Ann Intern Med. 2007;146(5):317-25. https://doi.org/10.7326/0003-4819-146-5-2 00703060-00004.

21. Vadaparampil ST, Jacobsen PB, Kash K, Watson IS, Saloup R, Pow-Sang J. Factors predicting prostate specific antigen testing among first-degree relatives of prostate cancer patients. Cancer Epidem Biomar. 2004;13(5):753-8.

22. Antoni MH, Lehman JM, Kilbourn KM, Boyers AE, Culver JL, Alferi SM, et al. Cognitive-behavioral stress management intervention decreases the prevalence of depression and enhances benefit finding among women under treatment for early-stage breast cancer. Health Psychol. 2001;20(1): 20-32. https://doi.org/10.1037/0278-6133.20.1.20

23. Mohamed EN, Böhmer S. Die deutsche Version der Benefit Finding Skala: Ihre psychometrischen Eigenschaften bei Tumorpatienten. Z Med Psychol. 2004;13(2):85-91.

24. Jansen L, Hoffmeister M, Chang-Claude J, Brenner H, Arndt V. Benefit finding and post-traumatic growth in long-term colorectal cancer survivors: prevalence, determinants, and associations with quality of life. $\mathrm{Br} J$ Cancer. 2011;105(8):1158-65. https://doi.org/10.1038/bjc.2011.335.

25. Ryff $C D$, Keyes $C L$. The structure of psychological well-being revisited. J Pers Soc Psychol. 1995;69(4):719-27.

26. Wanzer MB, Simon KG, Cliff NJ. Interpreting cancer survivors' perceptions of the survivor label through social identity and communication accommodation theories. Health Commun. 2021:1-9. https://doi.org/10.1 080/10410236.2021.1909263.

27. Bell K, Ristovski-Slijepcevic S. Cancer survivorship: why labels matter. J Clin Oncol. 2013;31(4):409-11. https://doi.org/10.1200/JCO.2012.43.5891.

28. Surbone A, Annunziata MA, Santoro A, Tirelli U, Tralongo P. Cancer patients and survivors: changing words or changing culture? Ann Oncol. 2013;24(10): 2468-71. https://doi.org/10.1093/annonc/mdt229.

29. Reiland SA, Clark CB. Relationship between event type and mental health outcomes: event centrality as mediator. Pers Indiv Differ. 2017;114:155-9. https://doi.org/10.1016/j.paid.2017.04.009.

30. Hruza M, Bermejo JL, Flinspach B, Schulze M, Teber D, Rumpelt HJ, et al. Longterm oncological outcomes after laparoscopic radical prostatectomy. BJU Int. 2013:111(2):271-80. https://doi.org/10.1111/j.1464-410X.2012.11317x.

31. Marzorati C, Riva S, Pravettoni G. Who is a cancer survivor? A systematic review of published definitions. J Cancer Educ. 2017;32(2):228-37. https:// doi.org/10.1007/s13187-016-0997-2

32. Khan NF, Harrison S, Rose PW, Ward A, Evans J. Interpretation and acceptance of the term 'cancer survivor': a United Kingdom-based qualitative study. Eur J Cancer Care (Engl). 2012;21(2):177-86. https://doi. org/10.1111/j.1365-2354.2011.01277.x.

33. Smith KC, Klassen AC, Coa Kl, Hannum SM. The salience of cancer and the "survivor" identity for people who have completed acute cancer treatment: a qualitative study. J Cancer Surviv. 2016;10(3):457-66. https://doi.org/10.1 007/s11764-015-0489-0.

34. Berry LL, Davis SW, Flynn AG, Landercasper J, Deming KA. Is it time to reconsider the term "cancer survivor"? J Psychosoc Oncol. 2019;37(4):41326. https://doi.org/10.1080/07347332.2018.1522411.

35. Cheung F, Lucas RE. Assessing the validity of single-item life satisfaction measures: results from three large samples. Qual Life Res. 2014;23(10):280918. https://doi.org/10.1007/s11136-014-0726-4.

36. Diamantopoulos A, Sarstedt M, Fuchs C, Wilczynski P, Kaiser S. Guidelines for choosing between multi-item and single-item scales for construct measurement: a predictive validity perspective. J Acad Mark Sci. 2012;40(3): 434-49. https://doi.org/10.1007/s11747-011-0300-3.

\section{Publisher's Note}

Springer Nature remains neutral with regard to jurisdictional claims in published maps and institutional affiliations. 